\title{
The Effects of Education and Family Planning Programs on Fertility in Indonesia
}

\author{
GUSTAVO ANGELES, DAVID K. GUILKEY, and THOMAS A. MrOZ \\ University of North Carolina at Chapel Hill
}

\section{Introduction}

Almost all studies of the impact of education on fertility find that the estimated reductions in fertility rates associated with increases in education levels dwarf the effects of most other explanatory variables, including those variables measuring the presence of family planning programs. In addition, research on other family developmental outcomes, such as children's schooling and health, indicate a strong association between a mother's education and beneficial effects for her children. Based on such estimated relationships, many analysts have concluded that programs to increase women's educational attainments might be the most effective way to stimulate reductions in fertility and improve children's lives in developing countries. There are, however, two serious deficiencies in most empirical research relating educational attainment to fertility that could give rise to invalid inferences about the causal impacts of education. First, many public programs, including family planning programs, may influence a woman's decisions about education or age at marriage, and therefore they might have large indirect effects. Second, few studies have controlled for the possible endogeneity of education that could arise because those individuals who complete more schooling might be a self-selected sample. In this article we study these issues in an evaluation of the roles mother's education and family planning programs play in lowering fertility in Indonesia.

We address the relevance of such endogeneity problems in the context of a model of the impact of education and family planning programs on fertility,

\footnotetext{
We gratefully acknowledge the support from the MEASURE Evaluation project, USAID Cooperative Agreement HRN-A-00-97-00018-00. We also acknowledge the Lembaga Demographi of the University of Indonesia for their efforts to collect part of the data used in this study. In particular, we acknowledge and thank Sri Haritaji Hatmadji and Omas Bulan Rajagugkguk for their help with the data. We appreciate the many useful comments made on earlier drafts of this article at the University of Pennsylvania, Johns Hopkins University, Yale University, Virginia Tech, the 2001 International Union for the Scientific Study of Population (IUSSP) meetings, and the 2003 IUSSP seminar on Poverty, Programs and Demographic Outcomes, especially those of Ronald Lee, Mark Montgomery, and John Strauss.
}

(C) 2005 by The University of Chicago. All rights reserved. 0013-0079/2005/5401-0007\$10.00 
using detailed, retrospective information available in the 1993 Indonesia Family Life Survey (IFLS) supplemented with historical statistics describing regional and temporal variations in school quality and public health expenditures. Like much of the literature assessing how controls for potential confounding influences affect the estimates of the importance of female education on child outcomes, we find that failing to address the potential for endogeneity in our sample appears to yield overestimates of the importance of a woman's education for reducing her fertility. The estimated direct effects of education, in fact, suggest that higher education levels often are associated with higher hazard rates of conceptions. The presence of family planning programs in a woman's village, especially if they have been in place for several years, appear to yield significant fertility reductions.

Our empirical approach also allows us to examine both the direct effects of family planning programs on fertility and the indirect effects through education. We find that the presence of family planning programs in a young woman's village when she is making her school attendance decisions increases substantially her educational attainment. Overall, simulations based on our estimates indicate that enhanced school characteristics provide relatively small incentives for women to attain more schooling, while the introduction of family planning programs appears to have important impacts on both educational attainment and fertility.

\section{Background}

At least since the pioneering work by Becker (1960) on the interactions of education and fertility, economists have considered a woman's education level to be a proxy for her shadow value of time. Since raising children is thought to be a time-intensive good, as female education levels rise one would expect to see families substitute out of children and into relatively less expensive, marketpurchased goods. There could be many other pathways by which female education affects fertility other than the substitution effect. For example, education may impart skills, such as literacy, that could alter how women perceive their role in society. Highly educated women might have more bargaining power when making contraceptive decisions within their families. Since women often wait until they have left school to begin families, staying in school longer postpones the age at first childbearing and thereby can lower the total fertility rate. Bledsoe, Johnson-Kuhn, and Haaga (1999) and Eloundou-Enyegue (1999) provide brief overviews of many of the mechanisms that could help to link higher education to lower fertility.

The empirical evidence in developing countries indicates that female education is associated with lower levels of fertility. This evidence has important 
policy implications. A 1992 World Bank development brief discussing the important gains from educating girls, for example, compared the efficiency of family planning and education programs for lowering fertility: "Educated women also choose to have fewer children. An extra year of female schooling reduced female fertility by about $5 \%$ to $10 \%$. So, a $\$ 30,000$ investment in educating 1,000 women would avert 500 births. How much does the typical family planning program spend to avert one birth? About $\$ 65$. Averting 500 births would cost about $\$ 33,000$, the same as educating an additional 1,000 girls, enough to justify education on family planning grounds alone" (World Bank 1992, 2). Such conclusions do not necessarily represent the views of the World Bank and its member countries, but the background paper for this brief was written by the World Bank's chief economist and vice president for development economics at that time (Summers 1992), so it surely carried considerable weight.

The evidence on the inverse relationship between women's education and fertility, however, is subject to several important qualifications. Jejeebhoy (1996), for example, finds for less developed countries with high levels of gender stratification that slight increases in education starting from low education levels can lead to increases in fertility. Only in the more developed countries do increases in education among those with the lowest education levels consistently yield fertility declines.

Others have questioned whether one can conclude that there is a causal relationship between higher education levels and lower fertility. In a recent paper using data from South Africa, Thomas (1999) examines the effects of female education on fertility. He notes that the evidence does indicate that a naive causal interpretation of the magnitude of the association is probably flawed and that failure to take account of the selection process underlying educational attainment is likely to lead to substantially incorrect inferences. Diamond, Newby, and Varle (1999) also suggest that the lower fertility rates of more educated women may reflect selection rather than a causal effect of education.

While many authors have recognized the self-selectivity of educational attainment (see Behrman [1990] and Strauss and Thomas [1996] for literature reviews), few authors have explicitly controlled for its endogeneity when it is used to explain fertility or related outcomes. There have been, however, several studies examining the robustness of the estimated impacts of education on labor market and child outcomes. Behrman and Birdsall (1983) study the impacts of education on wages in Brazil. They use a simple Mincer schooling choice model augmented by variations in school quality. Their theoretical model suggests that if higher school quality leads to more education, then 
there will tend to be overestimates of the impact of schooling on wages when one ignores the quality dimension. Their empirical analysis strongly supports this theoretical implication; the impact of years of school on wages falls by almost one half after they control for school quality. Angeles (1997) found that controlling for the endogeneity of education reduced the estimated return to schooling on labor market outcomes by nearly one half in Peru. Duflo (2001), in a study of the returns to education in Indonesia, however, finds that the estimated returns to education either remain unchanged or increase slightly after controlling for the endogeneity of individuals' schooling. Behrman and Rosenzweig (2002), in a somewhat different context, find that controlling for the endogeneity of a mother's education level changes the sign of the impact of her education on her children's educations from positive and significant to negative and insignificant.

The literature examining the indirect effects of family planning programs is less well developed. In part, this is due to data limitations arising from the relatively recent introduction of wide-scale family planning programs. Only during the past decade would one have been able to link data on family planning programs to women's education and their subsequent fertility. Angeles, Guilkey, and Mroz (1998), in a study for Tanzania, show that access to family planning programs early in a woman's life can have lasting effects on her fertility in addition to the effects of current access to family planning facilities. They did not, however, specify the mechanisms that could result in these long-term impacts. In a study of Bangladesh, Foster and Roy (1997) find important family planning program effects on reducing women's fertility and increasing their children's education associated with the Matlab experiment. This study had the advantage of being able to treat program inputs exogenously, but the data are not of sufficient duration to trace through the effects of these higher education levels on the children's subsequent fertility behaviors.

In the absence of experiments like the Matlab interventions, when assessing program impacts it is important to determine whether the provision of programs to particular areas might have been governed by location-specific factors that are related to the outcomes of interest. If the programs are targeted with their presence being associated with characteristics not observed by the researcher, there could be important biases in studies that simply relate outcomes to the presence of programs. Rosenzweig and Wolpin (1988) demonstrate that the impact of public programs might be seriously biased if unobserved characteristics of the program distribution mechanism are correlated with outcome variables such as health and fertility.

Angeles et al. (1998) develop an empirical model of life cycle fertility that 
accounts for individual heterogeneity as well as models the endogenous determination of family planning services in communities in Tanzania. Their empirical modeling approach recognizes that there might be particular unmeasured features of communities that could be related to the fertility of women within the community as well as to the propensity for the government to place family planning programs within the community. Their results indicate that such selective placement of family planning programs does have important effects on a researcher's ability to measure the programmatic effects. Without controlling for the endogeneity of the placement of the family planning facilities, Angeles et al. found that hospitals were the most important type of facility for providing effective family planning services. After controlling for the endogeneity of the timing of the placement of the programs, they found that hospitals providing family planning services had little impact on individual fertility outcomes, while health centers providing family planning services appeared to have large fertility reducing effects.

Pitt, Rosenzweig, and Gibbons (1993) and Gertler and Molyneaux (1994) note the targeted nature of the Indonesian family planning program and estimate community-level fixed-effects models to measure the impact of family planning programs on fertility. Gertler and Molyneaux's major conclusion is that, after controlling for program endogeneity, program effects on fertility are not significant even though simple methods indicate a significant negative impact on fertility for health centers. Pitt et al., however, find that simple methods yield a significantly positive impact for family planning programs on fertility. The effect becomes negative but insignificant when one controls for the endogeneity of program placement. Endogeneity of program placement in Indonesia could certainly be an important issue.

The Pitt et al. (1993) and Gertler and Molyneaux (1994) studies examine program impacts over a 5- or 6-year period in the early 1980s. This time period is almost 10 years after the initiation of the Indonesian family planning program. In addition, a massive expansion of the educational system in Indonesia also took place in the 1970s and early 1980s. Both papers examine change in fertility as a function of program changes during a period in which change was much more gradual than it had been earlier. This lack of variability might explain why the two studies were unable to uncover significant estimates of the program impacts.

In this article, we examine a much longer period of time, one that starts near the beginning of the expansion of services in Indonesia in the 1960s and ends in 1993. Our approach allows us to examine annual decisions made by women as a function of the current and past program environment. We can better match the timing of the introduction of services to fertility decisions 
made by respondents - $\mathrm{a}$ factor that we found to be crucial in uncovering program effects in both Tanzania and Peru (Angeles et al. 1998, forthcoming).

\section{Empirical Model}

Angeles, Guilkey, and Mroz (2004) develop a theoretical model for investments in schooling, timing of marriage, and the spacing and number of children that is the basis for the empirical model described in this section. The model is an extension of Goldin and Katz (2000, 2002), who present a simple model of how improvements in contraceptive technology can lead to changes in career choices, the timing of marriage, and age at first birth. Due to space constraints, the full model is not presented here.

This theoretical model, however, does have some important implications, and several of these have been mostly overlooked in the literature. First, better contraceptive knowledge, because it does reduce the probability of overshooting one's ideal family size, should reduce the expected number of children that would be born. Second, it is not necessarily the case that those with higher education levels will have smaller family sizes; the economic model recognizes that there can be important income effects as well as substitution effects. Third, it need not be the case that increased contraceptive knowledge will result in women optimally choosing higher education levels. Fourth, increases in contraceptive knowledge might have larger education impacts on those who would have chosen lower education levels in the absence of the increased knowledge. The magnitudes and directions of nearly all of these impacts on fertility are empirical questions.

\section{A. Overview}

Our empirical model uses a maximum likelihood procedure to estimate the determinants of a woman's schooling, age at marriage, and fertility outcomes. Starting at age 7 , a woman makes a decision each year about whether she wants to continue in school for another year. This decision depends upon year effects, her age, the quality of the schools in her local area, and indicators for how long each of three types of family planning services have been in her community of residence. It is the latter, community-level exposure to family planning variables, that we assume captures the woman's knowledge about contraceptive practices. Note that, at the youngest ages, we do not need to assume that the woman actually knows precisely about contraception. All that is required here is that the woman, or her parents if they are making the schooling decisions for her, believes that she will be better able to control her future fertility when there have been local examples of individuals having access to contraception for controlling fertility. We allow for there to be separate 
effects of whether there were family planning programs in her place of residence at age 7 when she started making her education decisions, along with the more usual indicators of the current availability of family planning programs in her community.

We also model two characteristics of her marriage, her age at marriage and the education level of her spouse. We use a discrete time hazard approach to model the age at marriage, where marriage decisions depend on completed schooling as of that age and whether she was in school during the preceding year. Marriage decisions, like the schooling decisions, also depend on the age7 and current exposures to facilities providing family planning. From a theoretical perspective, it is possible that better contraceptive knowledge could lead to an earlier age at marriage if delayed marriage had been used as a substitute for contraception in reducing family size. We model the years of education of the spouse as being determined by the same set of time-varying and person-specific variables as we used to model the woman's own education level.

We model the woman's fertility experiences starting at age 10 with annual logit events for whether the woman had a conception that led to a live birth. Each of these annual outcomes depends on her age, her and her husband's education levels, marital status, and current number of children, as well as characteristics of the woman's current and past exposure to family planning facilities. As for all the other outcomes, we allow the presence of family planning facilities in her place of residence when she was age 7 to have a separate impact from whether there were family planning services currently available in her community. We do this because we want to allow for the possibility that contraceptive knowledge when she was young could have helped to shape her life cycle plans about childbearing.

Given the evidence discussed above about the potential endogeneity of family planning facilities in Indonesia, in preliminary versions of our analysis we also controlled for the endogeneity of the timing of the placement of the facilities, using an approach similar to that used by Angeles et al. (1998). However, we did not find evidence of endogenous placement of family planning programs. One possible explanation for this is that we used detailed regional controls as determinants of all of the outcomes. In fact, in preliminary work, we found strong evidence of program endogeneity when these regional controls were omitted from the empirical model. On the basis of these findings, we treat the presence of family planning facilities as exogenous and include regional dummy variables in our final model.

By using a maximum likelihood framework, we are able to control for the endogeneity of the prior, individual-level outcomes such as schooling, marital status, and prior births on subsequent outcomes. We do this by using discrete 
approximations to individual-level unobserved determinants of all outcomes, as suggested by Heckman and Singer (1984; see also Mroz and Guilkey 1995; and Mroz 1999). We now discuss the stochastic specification of each equation in the model.

\section{B. Fertility}

The main equation of interest is the fertility equation. It is specified in the following logistic form:

$$
\begin{aligned}
& \operatorname{Pr}\left(B_{i j t}=1 \mid X_{i j t}^{B}, S_{i j t}, P_{j t}, Z_{j t}^{B}, \mu_{j}^{B}, \omega_{i j}^{B}\right) \\
& \quad=\operatorname{Logit}\left(X_{i j t}^{B} \delta^{B}+S_{i j t} \lambda^{B}+P_{j t} \alpha^{B}+Z_{j t}^{B} \beta^{B}+\mu_{j}^{B}+\omega_{i j}^{B}\right),
\end{aligned}
$$

where the subscripts denote woman $i$ from community $j$ at time $t$ and Logit (.) is the logit cumulative distribution function. The dependent variable, $B_{i j t}$, takes the value of one if a conception leading to a live birth occurs for woman $i$ in community $j$ at year $t$, and zero otherwise. The conception probability in each year is influenced by observed personal characteristics $\left(X_{i j t}^{B}\right)$ such as the woman's age and the number of children in her family at each year, the number of years of education $\left(S_{i j t}\right)$, the presence of family planning programs in the community $\left(P_{j t}\right)$, and other observed community characteristics $\left(Z_{j t}^{B}\right)$. The empirical model that we estimate incorporates time effects to capture systematic changes associated with time.

Fertility can also be influenced by individual characteristics that are unobserved by the researcher. The term $\omega_{i j}^{B}$ is included to capture time-invariant individual heterogeneity. It represents woman-specific unobserved factors that affect the conception propensity through time, such as the degree of fecundability, parental background, or motivation for family-oriented or labor market-oriented activities. There may also be community characteristics, such as group preferences for large or small families or the degree of support for family planning by community leaders, that also influence a woman's fertility but are not observed by the researcher. They are represented by $\mu_{j}^{B}$. The impact of any of these unobserved factors could vary through time, but this possibility is ignored in this analysis.

It is likely that some unobserved factors influencing fertility $\left(\omega_{i j}^{B}\right)$ also influence the level of schooling $\left(S_{i j t}\right)$, marital status, prior fertility, and the husband's education level. If that is the case, there will be correlations between these background characteristics and the term $\omega_{i j}^{B}$. Estimation of equation (1) by single-equation methods, which do not control for correlation between explanatory variables and unobservables, will most likely generate biased and inconsistent estimates. We allow for the two types of unobserved components 
to be potentially correlated with the unobserved factors influencing the schooling, marriage, and husband's educational attainments, and we estimate jointly the determinants of these background characteristics and the annual fertility measures. In this way we can obtain consistent estimates of the impacts of these possibly endogenous background characteristics on fertility.

For the fertility equation, we will assume that the probability of a conception is zero for years when the woman is less than 10 years of age. It is also important to note that, due to the sample design of the IFLS, the fertility equation is estimated only for ever-married women at the time of the survey. Controls for such potential sample selectivity bias are automatically included in the model because we allow for unobserved, but possibly correlated, individual-level random effects to influence marriage and fertility. The fertility model, then, is a discretetime annual renewal model of conceptions leading to live births.

\section{Education of the Woman and Her Spouse}

The education equation controls for the potential endogeneity of the schooling variables in the fertility and marriage equation and enables us to measure the effect of family planning programs on education. We model education using a discrete-time hazard model of continuation of school attendance. This framework enables us to include time-varying information that influences the timing of schooling decisions. We assume that all women start school at age 7 and attend school continuously until they reach their years of education as declared at the time of the survey. This assumption implies that women complete one grade of school for each year they attend a school, and it is clearly false. Unfortunately, there is no retrospective information available on the successful completion of school for each year, nor is there information on the number of years the woman actually attended school. Even if we integrated over all possible paths of grade progression and retention that could lead to the woman's stated years of school completed, we would still need to make strong and arbitrary assumptions about the underlying grade-retention processes. Instead, we impose this simplifying assumption of continuous school progression.

The school attendance equation is specified as

$$
\begin{aligned}
& \operatorname{Pr}\left(E_{i j t}=1 \mid E_{i j, t-1}=1, X_{i j t}^{E}, P_{j t}, Z_{j t}^{E}, \mu_{j}^{E}, \omega_{i j}^{E}\right) \\
& \quad=\operatorname{Logit}\left(X_{i j t}^{E} \delta^{E}+P_{j t} \alpha^{E}+Z_{j t}^{E} \beta^{E}+\mu_{j}^{E}+\omega_{i j}^{E}\right),
\end{aligned}
$$

where the dependent variable $E_{i j t}$ is equal to one if woman $i$ from community $j$ at time $t$ is in school conditional on not having terminated her schooling in the previous time period and zero if she decides not to continue attending school. The schooling continuation decision is influenced by observed personal 
characteristics $\left(X_{i j t}^{E}\right)$, the presence of family planning programs in the community $\left(P_{j t}\right)$, and other observed community characteristics $\left(Z_{j t}^{E}\right)$, including school characteristics.

The term $\mu_{j}^{E}$ represents community unobservables that influence the schooling decision. The term $\omega_{i j}^{E}$ represents time-invariant, woman-specific factors that affect her decision to continue her schooling-such as her level of motivation or parental background-but that are unobservable to the researcher. It is likely that there may be overlap between the unobservables that affect her fertility and schooling, and that is modeled by allowing the $\omega$ 's in the two equations to be correlated. Formally, the schooling model is a discrete-time annual hazard model of the age (time) of leaving school. ${ }^{1}$ By including this schooling outcome equation in the model one can examine the effect of family programs on education and, therefore, the indirect program effects on fertility.

We use a nearly identical approach for modeling the number of years of schooling of the woman's husband (if she marries). We use the same sets of explanatory variables and assume that the husband was exposed to the same levels of the time-dated variables that the woman would have been exposed to. In addition, we also allow the woman's level of education at the time of her marriage to be a determinant of her husband's education. Because of this, one should not interpret the husband's schooling level as a true hazard process describing the decisions about when to leave school. It is more of an equilibrium relationship, and the time-dated information on school characteristics in the husband's education model helps to describe the set of potential spouses for the woman. In preliminary studies, treating the husband's education as exogenous had only minor impacts on the estimated coefficients.

\section{Ever Married}

The IFLS recorded fertility histories only for ever-married women, and so in this study only women who married at least once can be included in the analysis of fertility outcomes. As discussed above, the equation for the timing of first marriage is included to control for potential selectivity of women into the ever-married group that could bias the estimates of the fertility equation. We model the event of first marriage in a discrete-time hazard framework. It is specified as

$$
\begin{aligned}
& \operatorname{Pr}\left(M_{i j t}=1 \mid M_{i j, t-1}=0, X_{i j t}^{M}, P_{j t}, Z_{j t}^{M}, \mu_{j}^{M}, \omega_{i j}^{M}\right) \\
& \quad=\operatorname{Logit}\left(X_{i j t}^{M} \delta^{M}+P_{j t} \alpha^{M}+Z_{j t}^{M} \beta^{M}+\mu_{j}^{M}+\omega_{i j}^{M}\right),
\end{aligned}
$$

\footnotetext{
${ }^{1}$ We actually model empirically the probability of continuing in school, i.e., one minus the hazard of leaving school.
} 
where the dependent variable $M_{i j t}$ is equal to one if the woman married for the first time at age $t$ and equal to zero if she had not married by that year. The hazard of first marriage depends on observed individual characteristics $\left(X_{i j t}^{M}\right)$, presence of family planning programs in the community $\left(P_{j t}\right)$, and other observed community characteristics $\left(Z_{j t}^{M}\right)$. Terms $\mu_{j}^{M}$ and $\omega_{i j}^{M}$ represent the community and individual unobservables. We control for potential sample selectivity by explicitly allowing a dependence among the individual unobservables influencing the event of marriage and those influencing the other outcomes. We assume that the probability of first marriage is zero for the years when the woman is less than 10 years of age. This is a discrete-time annual hazard model for the age at first marriage.

\section{E. Unobserved Heterogeneity, Endogeneity Controls, and the Likelihood Function}

Equations (1) and (3) plus two versions of equation (2) (one each for the woman's and her husband's education level) are jointly estimated using maximum likelihood estimation procedures. We approximate the joint distribution of the unobservables using a semiparametric discrete factor method (Heckman and Singer 1984; Mroz and Guilkey 1995; Mroz 1999). The discrete factor method has the advantage that the parameters defining the discrete distribution are estimated jointly with the other parameters of the model. Unlike more parametric specifications of the error structure, such as multivariate normality, here the distributions of the unobserved factors influencing fertility, education, program service placement, and marriage are estimated using all the information available on these processes. We use an unrestricted, discrete multivariate distribution for the unobserved factors. This provides a flexible specification of the unobservables affecting the different processes and the relationships among them.

The distribution of the individual random effects with $Q$ points of support is specified as

$$
\begin{gathered}
\operatorname{Pr}\left(\omega_{i j}^{B}=\omega_{1 q}, \omega_{i j}^{E_{w}}=\omega_{2 q}, \omega_{i j}^{E_{n}}=\omega_{3 q}, \omega_{i j}^{M}=\omega_{4 q}\right)=\pi_{I}(q), \\
\quad \text { for } q=1,2,3, \ldots, Q .
\end{gathered}
$$

Similarly, the distribution of the community random effects with $R$ points of support is specified as

$$
\begin{gathered}
\operatorname{Pr}\left(\mu_{j}^{B}=\mu_{1 r}, \mu_{j}^{E_{w}}=\mu_{2 r}, \mu_{j}^{E_{m}}=\mu_{3 r}, \mu_{j}^{M}=\mu_{4 r}\right)=\pi_{C}(r), \\
\quad \text { for } r=1,2,3, \ldots, R .
\end{gathered}
$$

The likelihood function for each individual woman is constructed by first specifying the likelihood function for each woman conditional on the 
unobserved factors. By the definition of the unobserved factors, there is conditional independence of events, and so the conditional likelihood is just the product of the likelihoods for each of the relevant individual-level outcomes at each age from age 7 until 1993, conditional on particular values of the individual and community unobservable factors for each outcome. The individual likelihood function that does not condition on the individual-level unobserved factor is constructed as a weighted sum of these conditional likelihoods for each individual, where the weights are the probabilities that the unobserved individual factors take on each combination of values. Each individual-level likelihood is weighted by the sample weights provided by the IFLS.

The individual likelihoods are still conditioned on the unobserved community factors. To remove these unobserved factors, the conditional community likelihood function is obtained by multiplying the unconditional individual likelihood functions for all individuals in the community. Then, the fully unconditional likelihood function is obtained by taking the weighted sum of the conditional community likelihoods, where the weights are the probabilities that the unobserved community factors take on their combination of values. We found that adding more than 10 points of support to either the individual- or community-level discrete factor distributions had almost no impact on the value of the likelihood function. Following Mroz's (1999) suggestion that one stop adding points of support when the likelihood value only increases trivially, we find that we need to use 10 points of support for each of these two distributions.

\section{The Data Set and Empirical Specification}

The main source of data for this study is the 1993 Indonesia Family Life Survey. The IFLS is one of the few surveys available that provide detailed information on fertility, schooling, migration histories, and local environments for a representative sample of a country's population. A key feature of the IFLS is that the household survey was accompanied by community and facility surveys that provide current and retrospective information on community characteristics and the availability of family planning, health, and schooling facilities that are relevant for the household survey respondents. As explained below, the data set was further augmented with community-level information from other sources so that statistical identification for the multi-equation model can be obtained.

The IFLS covered 13 of the 27 provinces in Indonesia with a total of 321 randomly selected enumeration areas included in the survey. Eighty-three percent of the population of Indonesia reside in these 13 provinces. Within each 
province the sampling strategy involved first selecting an enumeration area, then households, and then household members. Both the male and female head of the household were interviewed, while some additional household members were selected for interviews. The IFLS provides individual-level sample weights that we use for the estimation. Detailed schooling and migration information was collected for all selected women age 15 or over. In addition, detailed marriage and fertility information was collected for selected evermarried women age 49 or younger at the survey date. Our analysis sample consists of 5,025 women ages 13-51 with complete schooling, migration, and marriage histories. ${ }^{2}$ Of these, 4,659 women were married at least once and had complete fertility histories.

Each interviewed ever-married woman was asked for the month and year of birth of every birth she had had. Using the information on the timing of births, we reconstructed the conception histories for each woman. The dependent variable in the fertility equation was constructed by following each woman every year from age 10 until the year of the survey, 1993, and recording whether she had a conception leading to a live birth in a particular year. A total of 113,995 woman-year observations are recorded in which 15,283 conceptions occurred. Since fertility histories are collected only for a nonrandom subset of individuals in the IFLS, we use the sample weights included with the data for the analysis of the fertility outcomes.

Education is included in the model using dummy variables for schooling levels. The education system of Indonesia consists of primary school (6 years), junior high school (3 years), senior high school (3 years), and higher education or university ( 2 or more years). Using the information on woman's age and the number of years she spent in school, it is possible to backdate the information on school attainment for every year of a woman's life. We assume that the woman entered school at age 7 and remained there until the reported number of years of education was obtained.

The IFLS recorded detailed information for birthplace, place of residence at age 12 , place of last marriage, and the destination of every migration move after age $12 .^{3}$ For every migration event, the women were asked the month and year of change of residence, as well as detailed information to identify the destination place, including whether it was urban or rural. This information

\footnotetext{
${ }^{2}$ While most women in the analysis sample were in the 15-49 age range at the time of the survey, there were three women ages 13,50 , and 51 who responded to the ever-married fertility and marriage questionnaire. These three women were kept in the analysis sample.

${ }^{3}$ The IFLS recorded migration moves if the change of residence involved crossing a village border line and lasted for 6 months or longer. Here, we assume that place of residence at age 7 is the same as the place of residence at age 12 .
} 
enables us to reconstruct the woman's place of residence for every year from age 7 until 1993. For simplicity, we define 26 regions that are the urban and rural areas of the 13 provinces covered by the IFLS. ${ }^{4}$ About $31.3 \%$ of the women in the analysis sample reported at least one change in place of residence by 1993 . The information on place of residence enables us to better match family planning program variables and other community characteristics to the fertility and schooling histories. To help control for the impacts of migration, we include as explanatory variables the number of times the woman had moved up to each age for the events under consideration and a dummy variable indicating whether the woman was currently living in the location where she was living at the time of the 1993 survey.

The IFLS has the advantage of providing information about the communities and sources of health services relevant to the respondents of the household questionnaire. The community information was obtained by interviewing the village leader and the head of the village women's group. In addition, the IFLS visited a sample of health facilities and obtained contemporaneous and retrospective information on facility characteristics and functioning. The sampled facilities were selected from lists provided by the household survey respondents. Women in each selected household were asked to provide the name and location of facilities they knew or had used as sources of family planning or health services. For each enumeration area, the household responses were compiled to create a list of relevant facilities. A sample of these was then visited. The IFLS contains information about five different types of health facilities or health care providers. We classify these into three types of providers. The first type, called a puskesma, includes government or auxiliary health centers. The second type, called a posyandu, includes community health posts. We collapse private clinics, doctor offices, and the practices of nurses, midwives, and paramedics into a third category that we label as "private providers."

A key feature of the IFLS facility questionnaire is that it recorded the year that each facility first offered modern family planning services. We assume that the facility has continuously offered services since the date of first introduction. We define the family planning program variables for every type of facility as the availability of at least one facility offering family planning services to the community at any given year. A total of 993 puskesmas; 899 posyandu;

\footnotetext{
${ }^{4}$ Very few migration movements had as their destination places sites that were outside the 13 IFLS provinces, and those stays were for a relatively short duration. Out of the 134,255 womanyear observations of the place of residence histories for the whole analysis sample, only $645 \mathrm{ob}-$ servations correspond to non-IFLS provinces.
} 
549 private clinics; and 892 practices of nurses, midwives, or paramedics were included in the IFLS sample.

It is important to note that the family planning program information is directly observed only for the communities that were included as part of the IFLS. This means that we would not have time-varying program information for a woman who migrated to one of these communities from a community that was not part of the IFLS for those time periods prior to her date of arrival. For these cases, we use time-varying regional averages of availability of services as proxies for the program service environment that the woman faced in those earlier years.

In order to provide additional information for the specification of our model, a special time series data set on regional characteristics was collected from censuses, intercensus surveys, and government reports. We use information on regional per capita government expenditures on development activities, regional per capita government expenditures on health, the proportion of national population in the region, regional population density, percentage of households with assets like radios in the region, and regional student-teacher ratios for primary and secondary schools. The government expenditures are expressed in real 1979 rupiahs.

The basic specification of the model includes a set of age and calendar-year dummies to control for time-varying factors influencing the four outcomes of the model. Table 1 presents descriptive statistics for the variables included in the model. We present statistics for the survey year 1993. However, as discussed above, many of the individual variables are actually time varying as we follow a woman through her reproductive life. We also simply present her age and the years of education of the respondent in 1993, even though an extensive set of dummy variables were used in the statistical model. Table 1 also contains descriptive statistics for the community- and regional-level variables. All of these variables are time varying, but we only present statistics for 1993. Even though, for example, we see that family planning was available to around 95\% of the communities in 1993, the means and standard deviations of the duration measures indicate tremendous variability in availability over time across communities.

We consider three types of family planning programs that can provide this information at each point in time (calendar year) about a woman's exposure to contraceptive knowledge: a puskesmas providing family planning services within 5 kilometers of the woman's village, a posyandu with family planning services in her village, and a private provider of family planning services within 5 kilometers of her village. We describe in detail the measures that we use as they relate to a puskesmas; in the empirical model we use identical constructs 
TABLE 1

DESCRIPTIVE STATISTICS

\begin{tabular}{|c|c|c|}
\hline Variable & Mean & SD \\
\hline \multicolumn{3}{|l|}{ Statistics for individual-level variables in $1993(N=5,023)$ : } \\
\hline Woman's age & 32.7103 & 8.2290 \\
\hline Woman's years of education & 5.6401 & 4.2297 \\
\hline Husband's years of education & 6.9897 & 4.0783 \\
\hline Urban resident & .4842 & .4998 \\
\hline Respondent ever migrated & .3132 & .4638 \\
\hline Number of moves & .5180 & .8871 \\
\hline Puskesmas with family planning present when woman age 7 & .1169 & .3213 \\
\hline Posyandu with family planning present when woman age 7 & .0317 & .1751 \\
\hline Private family planning present when woman age 7 & .0770 & .2667 \\
\hline Urban resident region 1 & .0344 & .1824 \\
\hline Urban resident region 2 & .0309 & .1730 \\
\hline Urban resident region 3 & .0283 & .1658 \\
\hline Urban resident region 4 & .0328 & .1783 \\
\hline Urban resident region 5 & .0000 & .0000 \\
\hline Urban resident region 6 & .0810 & .2729 \\
\hline Urban resident region 7 & .0719 & .2583 \\
\hline Urban resident region 8 & .0169 & .1290 \\
\hline Urban resident region 9 & .0818 & .2741 \\
\hline Urban resident region 10 & .0325 & .1772 \\
\hline Urban resident region 11 & .0430 & .2029 \\
\hline Urban resident region 12 & .0311 & .1735 \\
\hline Urban resident region 13 & .0313 & .1740 \\
\hline Rural resident region 1 & .0488 & .2154 \\
\hline Rural resident region 2 & .0179 & .1327 \\
\hline Rural resident region 3 & .0225 & .1483 \\
\hline Rural resident region 4 & .0082 & .0900 \\
\hline Rural resident region 5 & .1059 & .3078 \\
\hline Rural resident region 6 & .0665 & .2492 \\
\hline Rural resident region 7 & .0450 & .2073 \\
\hline Rural resident region 8 & .0330 & .1788 \\
\hline Rural resident region 9 & .0611 & .2396 \\
\hline Rural resident region 10 & .0227 & .1489 \\
\hline Rural resident region 11 & .0157 & .1244 \\
\hline Rural resident region 12 & .0159 & .1252 \\
\hline Rural resident region 13 & .0209 & .1431 \\
\hline \multicolumn{3}{|l|}{ Statistics for community-level variables in $1993(N=321)$ : } \\
\hline Puskesmas with family planning currently present & .9595 & .1974 \\
\hline Posyandu with family planning currently present & .9720 & .1653 \\
\hline Private family planning currently present & .9502 & .2180 \\
\hline Number of years puskesmas with family planning in community & 14.5452 & 6.7128 \\
\hline Number of years posyandu with family planning in community & 9.5919 & 4.5851 \\
\hline Number of years private family planning in community & 11.7788 & 7.0457 \\
\hline \multicolumn{3}{|l|}{ Statistics for regional-level variables in $1993(N=13)$ : } \\
\hline Student-teacher ratio in primary schools $\left(\times 10^{-1}\right)$ & 2.1830 & .3921 \\
\hline Student-teacher ratio in secondary schools $\left(\times 10^{-1}\right)$ & 1.3853 & .1688 \\
\hline Student-school ratio in primary schools $\left(\times 10^{-2}\right)$ & 1.8278 & .4364 \\
\hline Student-school ratio in secondary schools $\left(\times 10^{-2}\right)$ & 3.3790 & .5768 \\
\hline Gross regional domestic product per capita in real 1979 rupiahs $\left(\times 10^{-3}\right)$ & .4318 & .3215 \\
\hline $\begin{array}{l}\text { Government expenditures on development per capita in real } 1979 \text { rupi- } \\
\text { ahs }\left(\times 10^{-3}\right)\end{array}$ & .4869 & 1.2945 \\
\hline $\begin{array}{l}\text { Government expenditures on education per capita in real } 1979 \text { rupiahs } \\
\left(\times 10^{-3}\right)\end{array}$ & .2357 & .4895 \\
\hline $\begin{array}{l}\text { Government expenditures on family planning per capita in real } 1979 \text { ru- } \\
\text { piahs }\left(\times 10^{-3}\right)\end{array}$ & .0108 & .0243 \\
\hline Government expenditures on health per capita in real 1979 rupiahs & & \\
\hline$\left(\times 10^{-3}\right)$ & .1428 & .3216 \\
\hline
\end{tabular}


to capture the impacts of posyandu and private providers. Angeles et al. (1998) use similar sets of measures for the impacts of family planning programs on fertility in their Tanzania study.

The first measure is an indicator (dummy) variable for whether there was a puskesmas in the woman's village. This measure, like both of the following two measures, is a time-varying variable that can influence fertility, marriage, and educational outcomes during a particular year. It is the type of contemporaneous measure that is used in most studies of the impact of family planning programs on fertility.

The second family planning program measure is intended to capture the length of exposure of the woman's community to family planning programs. The motivation for this measure is the idea that the longer a puskesmas has been offering family planning services within a community, the more likely it is that any woman living there would know about modern contraceptive methods. A simple linear duration term would only crudely approximate this type of effect, as one would expect the impact of additional exposure to decline at higher exposure levels. To incorporate this type of diminishing effect, we use the term [years/(years $+d$ )] as a regressor in each logit argument, where years measures the number of years since a puskesmas first started offering family planning services in the village. Preliminary models suggested that setting $d$ to 8 yielded a slightly higher likelihood function value than setting $d$ equal to either 7 or 9 .

The simple economic model implies that knowledge about family planning can be quite important when a woman is making her early educational decisions. The third family planning measure we use attempts to measure this exposure to family planning when the woman began making her education decisions. To do this we use a simple dummy variable for whether there was a puskesmas in her village when she was 7 years old. We did estimate preliminary versions of this model that replaced this dummy variable for exposure at age 7 with one indicating exposure at age 10 or age 12, and we found almost no substantive differences. Note that the sum of the coefficients on the two dummy variables and the duration term describes the impact of a long-term puskesmas on each outcome.

We also construct three similar measures of exposure to family planning programs for exposure provided by posyandu and for exposure provided by private providers. These nine measures capture the full range of family planning effects that we consider in this study. Note that we use these nine measures as determinants of each of the four outcomes that we model.

It is important to note that all of the community and regional variables are time varying and that they varied a great deal in the years covered by our 
study. This was a period of a major increase in investments in health, family planning, and education in Indonesia. In dynamic models it is variation through time in such variables that provides identification for the model. The reason for this is that panel data relationships such as those examined here implicitly provide more identification conditions than one might infer by simply counting the number of contemporaneous exogenous variables excluded from the structural equation of interest (e.g., instruments). There are two primary reasons for this.

First, consider the case examined by Bhargava (1991) in which one is willing to impose structural parameter stability over the time dimension. As Bhargava (1991) demonstrated, every lag of each instrument could have a separate effect on the contemporaneous value of the endogenous explanatory variables. This time dimension for the exogenous time-varying instruments creates a multiplicity of instruments associated with each exclusion restriction, resulting in significantly more variables to control for endogeneity. Bhargava demonstrates that overidentification can be obtained under quite weak conditions.

A second source of additional identification arises in the context of dynamic nonlinear models. Mroz and Surette (1998) discuss this in more detail. They exploit the fact that, in dynamic models, variations in the time ordering of the exogenous variables provide even higher degrees of overidentification than would be obtained by a simple reference to Bhargava's (1991) observation as discussed above. The basic idea underlying this additional identification argument is that, in dynamic nonlinear models of the type used here, the impact of a lagged exogenous variable, say at $(t-s)$, on a current endogenous variable, at $t$, depends crucially on the entire time series of all exogenous variables before $t-s$ and between $t-s$ and $t$. For example, the impact of lagged exogenous variable at $(t-s)$ on a cumulative endogenous explanatory variable at time $t$ will depend differently on the values of the same exogenous variable dated at $(t-s-1)$ and at $(t-1)$. The calendar time patterns of other exogenous variables will also modify the impact of this variable at $(t-s)$, leading to dramatic increases in the degree of identification.

By using an explicit sequential dynamic modeling framework, one can incorporate all such interactions that depend on the precise timing and sequencing of the values of the varying exogenous variables. The maximum likelihood approach we use here automatically incorporates these interactions among the time series properties of the sets of exogenous variables. They do so efficiently, without one having to resort to including numerous time-varying interactions of the exogenous variables in an arbitrary fashion, as would be the case with a more static instrumental variables approach. Our models also 
incorporate some contemporaneous exclusion restrictions, and these are discussed below in our discussion of the estimates.

It is, however, important to note that there are limitations to this identification strategy. While at first glance it may seem reasonable to exclude the past values of exogenous variables as determinants of current outcomes, in a stochastic environment economic agents might use the past values of the exogenous variables to help forecast the distributions of the future values of these exogenous variables. If this were the case, then one could not justify the dynamic exclusion restrictions. However, if agents believe that first-order Markov processes generate the future values of exogenous variables, then the above discussion about parameter identification carries through (Mroz and Weir 2003). A second shortcoming of this identification strategy is that it does require the researcher to impose a joint distribution for the unobservable factors influencing outcomes over the course of many years for an individual. Any feasible distributional assumption would necessarily be quite restrictive, and it clearly would be quite difficult to justify any such assumption. Our use of semiparametric, multivariate, unobserved heterogeneity, however, does reduce somewhat our reliance on untestable assumptions. Third, the permanent/transitory error structure we impose on the joint distribution is quite restrictive. Note, however, that such simplifying assumptions are routinely used in fixed effect models, where only slight violations of such assumptions could yield considerable bias.

\section{Estimates}

Table 2 provides summary information concerning the model estimates. The baseline model we consider includes 279 parameters for modeling the four outcomes; 92 of these come from regional dummy variables. Using 10 points of support for each of the two heterogeneity distributions adds 90 parameters to the model, and the log-likelihood function value increases by over 1,300 points. The estimated probabilities for each point of support are also displayed in this table. While a standard likelihood ratio test does not provide the correctly sized tests in this instance, it is informative to see how large of an increase in the log-likelihood would be needed for one to reject the insignificance of a model with 90 additional parameters. An increase in the loglikelihood of only 75 points would indicate significance at under the 0.0001

level for an addition of 90 parameters. The addition of heterogeneity to the empirical model clearly improves the fit of the model.

Estimation results for the four-equation system are presented in table 3 (conception equation), table 4 (education hazard equations for the woman and her husband), and table 5 (marriage hazard equation). Endogenous variables 
TABLE 2

SUMMARY STATISTICS FOR MODELS WITH AND WITHOUT ENDOGENEITY/HETEROGENEITY CONTROLS

\begin{tabular}{|c|c|c|}
\hline & $\begin{array}{l}\text { Value of the } \\
\text { Likelihood Function }\end{array}$ & $\begin{array}{l}\text { Number of } \\
\text { Parameters }\end{array}$ \\
\hline Heterogeneity-corrected model & $-68,203.59$ & 369 \\
\hline Simple model & $-69,508.22$ & 279 \\
\hline Gain from heterogeneity corrections & $1,304.63$ & \\
\hline \multirow[t]{3}{*}{ Increase in parameters estimated } & & 90 \\
\hline & \multicolumn{2}{|c|}{ Estimated Heterogeneity Distributions } \\
\hline & $\begin{array}{l}\text { Community-Level } \\
\text { Probability Weight } \\
\end{array}$ & $\begin{array}{c}\text { Individual-Level } \\
\text { Probability Weight } \\
\end{array}$ \\
\hline Point 1 & .1865 & .0144 \\
\hline Point 2 & .2745 & .1666 \\
\hline Point 3 & .2938 & .5817 \\
\hline Point 4 & .0712 & .0287 \\
\hline Point 5 & .0191 & .1529 \\
\hline Point 6 & .0237 & .0313 \\
\hline Point 7 & .0322 & .0096 \\
\hline Point 8 & .0131 & .0137 \\
\hline Point 9 & .0257 & .0006 \\
\hline Point 10 & .0602 & .0005 \\
\hline
\end{tabular}

Note. The estimated points of support for the heterogeneity distributions are reported in the tables associated with each of the four outcomes that we model.

that appear on the right-hand side of each equation are in the top rows of the tables immediately following the constant terms and are labeled as such. All equations except that describing the woman's education level contain explicit endogenous explanatory variables. The conception equation includes children ever born, whether the woman has ever been married and whether she is currently married, whether she was in school last year, and the level of education for the woman and her spouse. The hazard equations for marriage and husband's education include the woman's level of education as an explanatory variable. Finally, the marriage hazard also includes a dummy for whether the woman was in school during the previous year.

The tables list individual-level variables first and then community- and regional-level variables. The community variables are the access to family planning measures that were discussed in detail above. The regional variables include regional gross domestic product; separate variables for regional expenditures on development, education, family planning, and health; and a set of four variables related to school quality-student-teacher ratios at primary and secondary schools and student-school ratios at primary and secondary schools. The conception equation includes 11 community and regional variables, excluding only the school quality variables that are hypothesized to act through the level of education of the woman and that of her spouse. The other three equations include all 15 community- and regional-level variables. 


\section{A. Estimates of the Coefficients Determining Fertility Outcomes}

The estimates of the coefficients determining the arguments to the annual probabilities of conception can be found in table 3. The first set of columns of this table come from the model that assumes independence (simple model), and the last two columns pertain to the model that corrects for heterogeneity and endogeneity (random effects). When comparing estimates from these two models, it is important to recognize that the heterogeneity terms are subsumed into the logistic error in the simpler model. Since a logit-type model imposes an error variance of $\pi^{2} / 3$, one cannot directly compare point estimates from the two estimation procedures. One can, however, adjust the estimates by using the estimated variances of the heterogeneity distributions or by examining ratios of parameters/effects across estimation models to remove the influence of arbitrary normalizations on comparisons. The total error variance in the conception hazard model for the random effects model is 1.17 times that for the simple model. Dividing the random effects estimates by the relative standard deviation, 1.08, allows for simple, direct comparisons across estimation approaches for this outcome. When testing for equality of effects across models, we normalize with respect to the coefficients of government expenditures on health. This effect is precisely estimated in each of the two estimation models.

The coefficient on the number of children ever born for each year at risk of conceiving measures how the woman adjusts her fertility in response to having additional children in her family. For both estimation procedures, an additional child appears to reduce the probability of a subsequent birth. The estimated impact from the model with heterogeneity controls, however, suggests a 6.5 times larger response by couples to family-building pressure. A Wald test for the equality of the relative effects from the two estimation procedures rejects the null hypothesis at the 0.01 level. ${ }^{5}$ The failure to control for heterogeneity, which could include differences in fecundity, as discussed in Mroz and Weir (1990), results in a severe understatement of how larger families attempt to reduce subsequent fertility, holding the woman's age constant. The coefficient on the dummy variable measuring whether the woman is currently married only increases by about $10 \%$ after controlling for unobserved heterogeneity.

A comparison of the coefficients on the woman's education dummy variables indicates that, after controlling for the endogeneity of education, those with

${ }^{5}$ We use a Wald test of the null hypothesis that the ratio of the relative effects of children ever born and government expenditures on health are equal. We construct the joint covariance matrix for the two sets of estimates using the formulas in Mroz (1987). In all subsequent tests for the effects on the probability of conception, we follow a similar approach. 
TABLE 3

RESULTS FOR CONCEPTION EQUATION

\begin{tabular}{|c|c|c|c|c|}
\hline \multirow[b]{2}{*}{ Variable } & \multicolumn{2}{|c|}{ Simple Model } & \multicolumn{2}{|c|}{ Random Effects } \\
\hline & Coefficient & SE & Coefficient & SE \\
\hline \multicolumn{5}{|l|}{ Individual-level variables: } \\
\hline Constant & -2.1558 & .2803 & -5.4864 & .5802 \\
\hline \multicolumn{5}{|l|}{ Endogenous variables: } \\
\hline Children ever born & -.0329 & .0126 & -.2333 & .0262 \\
\hline Ever married & 1.4633 & .1480 & 1.7834 & .1614 \\
\hline Woman primary education & -.0133 & .0446 & .1276 & .0640 \\
\hline Woman junior high education & -.0715 & .0552 & .1456 & .0859 \\
\hline Woman senior high education & -.1139 & .0616 & .1226 & .1016 \\
\hline Woman college education & .0318 & .0743 & .3121 & .1145 \\
\hline Husband primary education & .2848 & .1173 & .2009 & .1332 \\
\hline Husband junior high education & .3454 & .1270 & .4229 & .1458 \\
\hline Husband senior high education & .4140 & .1265 & .6483 & .1444 \\
\hline Husband college education & .4290 & .1262 & .7826 & .1538 \\
\hline In school last year & -.9011 & .1015 & -.6041 & .1037 \\
\hline Currently married & .7392 & .0587 & .5776 & .0620 \\
\hline Woman age 10 & -3.2841 & .2853 & -4.4984 & .5842 \\
\hline Woman age 11 & -1.6580 & .1938 & -2.0590 & .1943 \\
\hline Woman age 12 & -1.4472 & .1469 & -1.8229 & .1535 \\
\hline Woman age 13 & -1.1914 & .1299 & -1.5562 & .1425 \\
\hline Woman age 14 & -.8197 & .1120 & -1.0854 & .1175 \\
\hline Woman age 15 & -.6198 & .0940 & -.8597 & .0994 \\
\hline Woman age 16 & -.3197 & .0732 & -.5285 & .0793 \\
\hline Woman age 17 & -.1987 & .0709 & -.3672 & .0742 \\
\hline Woman age 18 & -.0780 & .0628 & -.2127 & .0658 \\
\hline Woman age 19 & -.0237 & .0672 & -.1179 & .0694 \\
\hline Woman age $21-22$ & -.0600 & .0532 & -.0263 & .0541 \\
\hline Woman age $23-24$ & -.1526 & .0510 & -.0177 & .0541 \\
\hline Woman age $25-26$ & -.2241 & .0527 & .0144 & .0606 \\
\hline Woman age $27-28$ & -.3291 & .0591 & .0108 & .0696 \\
\hline Woman age $29-30$ & -.4656 & .0662 & -.0303 & .0842 \\
\hline Woman age $31-35$ & -.7337 & .0659 & -.1542 & .0876 \\
\hline Woman age $36-40$ & -1.4140 & .0872 & -.6820 & .1008 \\
\hline Woman age $41-45$ & -2.2504 & .1396 & -1.4355 & .1566 \\
\hline Woman age $46-49$ & -2.4711 & .2720 & -2.2059 & .4905 \\
\hline Respondent ever migrated & .0217 & .0663 & -.1005 & .0808 \\
\hline Number of moves & -.0191 & .0333 & .0214 & .0416 \\
\hline Living in 1993 community this year & .0052 & .0596 & -.0038 & .0749 \\
\hline Urban resident & -.1082 & .1881 & -.1230 & .2811 \\
\hline Urban resident region 1 & .1976 & .2337 & .1740 & .3380 \\
\hline Urban resident region 2 & .0615 & .2241 & .0075 & .3245 \\
\hline Urban resident region 3 & .0598 & .2240 & -.0177 & .4674 \\
\hline Urban resident region 4 & -.2022 & .2292 & -.3336 & .3308 \\
\hline Urban resident region 6 & -.1865 & .2339 & -.2588 & .3189 \\
\hline Urban resident region 7 & -.4089 & .2263 & -.6014 & .3157 \\
\hline Urban resident region 8 & -.5563 & .2245 & -.7105 & .3247 \\
\hline Urban resident region 9 & -.5375 & .2211 & -.5431 & .3224 \\
\hline Urban resident region 10 & -.2383 & .2270 & -.3464 & .3536 \\
\hline Urban resident region 11 & .1800 & .2297 & .3031 & .3382 \\
\hline Urban resident region 12 & -.2439 & .2269 & -.2735 & .3314 \\
\hline Urban resident region 13 & -.1296 & .2428 & -.0459 & .3260 \\
\hline Rural resident region 1 & -.0332 & .1083 & -.0762 & .1373 \\
\hline Rural resident region 2 & .1142 & .1241 & .0807 & .1554 \\
\hline Rural resident region 3 & .1091 & .1248 & .0525 & .1980 \\
\hline Rural resident region 4 & .0688 & .1836 & .0196 & .2040 \\
\hline Rural resident region 6 & -.2119 & .1055 & -.3460 & .1373 \\
\hline Rural resident region 7 & -.2713 & .1171 & -.3987 & .1382 \\
\hline Rural resident region 8 & -.3704 & .1872 & -.5272 & .2472 \\
\hline
\end{tabular}


TABLE 3 (Continued)

\begin{tabular}{|c|c|c|c|c|}
\hline \multirow[b]{2}{*}{ Variable } & \multicolumn{2}{|c|}{ Simple Model } & \multicolumn{2}{|c|}{ Random Effects } \\
\hline & Coefficient & SE & Coefficient & SE \\
\hline Rural resident region 9 & -.5046 & .1054 & -.4754 & .1316 \\
\hline Rural resident region 10 & -.2992 & .1295 & -.3830 & .1515 \\
\hline Rural resident region 11 & .2791 & .1424 & .2321 & .1595 \\
\hline Rural resident region 13 & .0508 & .1323 & .0582 & .1599 \\
\hline Year 1965-69 & .1062 & .0942 & .1396 & .0963 \\
\hline Year 1970-74 & .0897 & .0975 & .1421 & .0990 \\
\hline Year 1975-79 & -.0146 & .0986 & .0482 & .1016 \\
\hline Year 1980-84 & -.1271 & .1110 & -.0462 & .1104 \\
\hline Year 1985-89 & -.3593 & .1262 & -.2764 & .1221 \\
\hline Year 1990-93 & -.6464 & .1487 & -.5817 & .1429 \\
\hline \multicolumn{5}{|l|}{ Puskesmas with family planning present } \\
\hline $\begin{array}{l}\text { Posyandu with family planning present } \\
\text { when woman age } 7\end{array}$ & .1539 & .1046 & .1111 & .1056 \\
\hline $\begin{array}{l}\text { Private family planning present } \\
\text { when woman age } 7\end{array}$ & .0811 & .0804 & .0020 & .0899 \\
\hline \multicolumn{5}{|l|}{ Community and regional variables: } \\
\hline $\begin{array}{l}\text { present } \\
\text { Posyandu with family planning currently }\end{array}$ & .0439 & .0480 & .0674 & .0463 \\
\hline present & .0494 & .0432 & .0385 & .0459 \\
\hline Private family planning currently present & .0043 & .0454 & .0155 & .0468 \\
\hline $\begin{array}{l}\text { Number of years puskesmas with } \\
\text { family planning in community } \\
\text { Number of years posyandu with family }\end{array}$ & .0713 & .1074 & -.2217 & .1128 \\
\hline planning in community & -.3319 & .1589 & -.4586 & .1612 \\
\hline \multicolumn{5}{|l|}{ Number of years private family } \\
\hline planning in community & -.0976 & .1156 & -.2685 & .1240 \\
\hline Gross regional domestic product & -.2257 & .1626 & -.2587 & .1809 \\
\hline Government expenditures on development & .0018 & .0047 & .0011 & .0055 \\
\hline Government expenditures on education & .0884 & .0837 & .0761 & .0919 \\
\hline Government expenditures on family planning & .1509 & 1.5549 & .2358 & 1.5729 \\
\hline \multirow[t]{4}{*}{ Government expenditures on health } & -.6250 & .2010 & -.6616 & .2172 \\
\hline & \multicolumn{4}{|c|}{$\begin{array}{l}\text { Unobserved Heterogeneity Effects } \\
\text { for the Random Effects Model }\end{array}$} \\
\hline & \multicolumn{2}{|c|}{ Community } & \multicolumn{2}{|c|}{ Individual } \\
\hline & Coefficient & SE & Coefficient & SE \\
\hline \multicolumn{5}{|l|}{ Point 1 (normalized to zero) } \\
\hline Point 2 & -.1768 & .0613 & 2.6825 & .6346 \\
\hline Point 3 & .1544 & .0555 & 3.1078 & .6463 \\
\hline Point 4 & .5659 & .0615 & 4.8664 & .6961 \\
\hline Point 5 & .2486 & .1003 & 3.8507 & .7024 \\
\hline Point 6 & .2494 & .0822 & 3.1047 & .6803 \\
\hline Point 7 & -.1440 & .0739 & 1.2581 & .9924 \\
\hline Point 8 & -.4585 & .1188 & .3358 & 5.0935 \\
\hline Point 9 & -.4358 & .1159 & -.0913 & .7379 \\
\hline Point 10 & .5016 & .1313 & -.1387 & .8140 \\
\hline
\end{tabular}


higher education levels have higher conception probabilities than those who did not complete primary school. In the model without the heterogeneity controls, only those with university education had higher fertility than those who did not complete primary school. A Wald test for the equality of the four coefficients across estimation methods, after normalization, rejects the null hypothesis at better than the 0.01 level, and three of the four coefficient comparisons are significantly different, with $t$-statistics over 2.0. The model with endogeneity controls clearly provides a much different view of the importance of increased female education as a policy tool for lowering fertility.

One possible explanation for why the endogeneity controls have such a large impact on the estimates comes from the sources of identification used to obtain the estimates from the two approaches. In the naive model, one is essentially comparing the fertility rates of those who had chosen higher education levels to those of individuals who did not complete primary school. The women who chose more education might have done so because they did not have strong (unobserved) tastes for large families, and so they knew they would have more use for human capital that would be rewarded in the labor market. In the model with the heterogeneity controls, it is the exogenous variations in the quality of the schools and in the availability of family planning that identify the impacts of increased education levels on fertility. The estimates from the model with endogeneity controls provide information about what would happen if one could increase exogenously a woman's education from less than completion of primary school to a higher level. Apparently, for this type of exogenous increase in education, the income effect outweighs the effect due to the change in the value of time.

The impact of increases in the husband's education is usually associated with income effects for fertility outcomes, and we see for both models that higher values of the husband's education lead to increases in the propensity to conceive and give birth. A Wald test of the null hypothesis of equality of the four relative effects across estimation approaches is rejected at least at the 0.01 level. The simple model appears to overestimate the impact of the male education when moving from uncompleted primary education to completion of primary education, but it underestimates the large positive effect of increases in the husband's education at higher education levels.

The coefficients on the dummy variables indicating the contemporaneous presence of each of the three family planning programs are not significantly different from zero at conventional significance levels. Additionally, it appears that the presence of any type of facility offering family planning services could lead to higher conception levels. It is, however, important to note that these coefficients cannot be interpreted without also taking into account the fact 
that we also control for the amount of time the family planning programs had been in the community. In fact, each of the three variables measuring the number of years that family planning has been in community have a significant, negative impact on fertility. The long-run effects of the three types of family planning programs can be calculated by summing the three effects for each program type. Each of the three long-run effects are negative, and as a group they are significantly different from zero at the 0.05 level. The long term impacts of posyandus and private family planning providers are fairly substantial $(-0.31$ and -0.25 , respectively), but the impact of a puskesma in the community is only about one fourth as large. These estimates imply substantial fertility reductions, as will be seen when we use simulations based upon these estimates to evaluate the overall impacts of the family planning programs.

\section{B. Estimates of the Coefficients Determining Women's Schooling Outcomes}

The first two columns in table 4 contain the estimates of the process describing the woman's schooling decisions. The coefficients correspond to a discretetime, annual "hazard" of continuing in school for another year. The school quality measures operate in the expected duration, with lower student per teacher ratios and larger schools making it more likely that the youth will continue in school. These effects are larger and more significant for secondary schools, but only the two measures of secondary school quality are individually significant at the $5 \%$ level.

For the most part, the family planning effects operate to increase the likelihood that the young woman continues on in school, with the three coefficients indicating contemporaneous presence of facilities and the three coefficients indicating their presence when the woman was age 7 all being positive. Only one of these is significantly different from zero. This lack of individual significance, however, is not unexpected, given that relatively few women in the data set had family planning facilities appear in their villages after they were age 7 and before they left school.

Two of the three effects of duration of exposure to family planning are negative, but none is significant. Despite these wrong-signed duration effects, the long-term puskesma and posyandu effects are large. The effect of the existence of a long-term posyandu, including the presence of such a facility when the woman was age 7 , is equivalent to about a five student per teacher decline in secondary schools, while the comparable impact of a long-term puskesma is the same as a 6.5 reduction in the student per pupil ratio. These are not small effects. The long-term impact of private facilities offering family planning services on education is quite close to zero. 
TABLE 4

RANDOM-EFFECTS RESULTS FOR EDUCATION EQUATIONS

\begin{tabular}{|c|c|c|c|c|}
\hline \multirow[b]{2}{*}{ Variable } & \multicolumn{2}{|c|}{ Woman } & \multicolumn{2}{|c|}{ Husband } \\
\hline & Coefficient & SE & Coefficient & SE \\
\hline \multicolumn{5}{|l|}{ Individual-level variables: } \\
\hline Constant & -5.8762 & 1.4657 & -2.9191 & 1.7972 \\
\hline \multicolumn{5}{|l|}{ Endogenous variables: } \\
\hline Woman primary education & & & -.7073 & .1357 \\
\hline Woman junior high education & & & -.1783 & .1811 \\
\hline Woman senior high education & & & .4290 & .2206 \\
\hline Woman college education & & & .1644 & .2992 \\
\hline Woman age 7 & 6.2558 & .4046 & 7.9836 & .5698 \\
\hline Woman age 8 & 7.3252 & .3884 & .6536 & .4468 \\
\hline Woman age 9 & 6.4660 & .3696 & 5.7110 & .4385 \\
\hline Woman age 10 & 6.0921 & .3475 & 5.3099 & .4296 \\
\hline Woman age 11 & 5.7150 & .3433 & 5.1948 & .4118 \\
\hline Woman age 12 & 5.6668 & .3445 & 5.3329 & .4088 \\
\hline Woman age 13 & 2.8350 & .2911 & 2.0147 & .3593 \\
\hline Woman age 14 & 3.7186 & .2777 & 3.0760 & .3525 \\
\hline Woman age 15 & 4.2709 & .2895 & 3.6239 & .3421 \\
\hline Woman age 16 & 2.6081 & .2450 & 1.7242 & .3037 \\
\hline Woman age 17 & 3.0186 & .2233 & 3.4013 & .3171 \\
\hline Woman age 18 & 3.7751 & .2801 & 3.7255 & .3276 \\
\hline Woman age 19 & -.1655 & .1684 & -1.3623 & .2173 \\
\hline Woman age 20 & .4946 & .2115 & .9301 & .2555 \\
\hline Respondent ever migrated & .3408 & .4670 & .3567 & .3474 \\
\hline Number of moves & -.0277 & .1397 & .0539 & .1350 \\
\hline Living in 1993 community this year & -.0432 & .4517 & .0548 & .3211 \\
\hline Urban resident & .5343 & .8608 & .4511 & 1.4308 \\
\hline Urban resident region 1 & .4141 & .9868 & -.0142 & 1.4947 \\
\hline Urban resident region 2 & .3164 & 1.0189 & -.4682 & 1.5217 \\
\hline Urban resident region 3 & .3928 & 1.2808 & .2243 & 1.5961 \\
\hline Urban resident region 4 & -.1141 & .9706 & -.5104 & 1.5283 \\
\hline Urban resident region 6 & .3763 & .9869 & .1892 & 1.5126 \\
\hline Urban resident region 7 & .8331 & 1.0257 & .4544 & 1.5375 \\
\hline Urban resident region 8 & .7860 & 1.0053 & .4579 & 1.5377 \\
\hline Urban resident region 9 & .0278 & .9668 & -.1971 & 1.5042 \\
\hline Urban resident region 10 & -.3422 & 1.2558 & .3415 & 1.6869 \\
\hline Urban resident region 11 & -1.0658 & 1.0107 & -.8092 & 1.4915 \\
\hline Urban resident region 12 & -.0982 & .9904 & .1203 & 1.5092 \\
\hline Urban resident region 13 & -.3748 & .9876 & -.3586 & 1.4983 \\
\hline Rural resident region 1 & .2180 & .3863 & .0695 & .3324 \\
\hline Rural resident region 2 & .4988 & .3799 & -.4063 & .3349 \\
\hline Rural resident region 3 & .6432 & .9040 & .4700 & .7171 \\
\hline Rural resident region 4 & 1.1434 & .5878 & .3282 & .4122 \\
\hline Rural resident region 6 & -.1482 & .3959 & -.1643 & .3358 \\
\hline Rural resident region 7 & .1762 & .4191 & -.1029 & .3544 \\
\hline Rural resident region 8 & .3902 & .5674 & -.1644 & .4278 \\
\hline Rural resident region 9 & -.2108 & .3904 & -.2381 & .3185 \\
\hline Rural resident region 10 & .0347 & .6968 & .2219 & .6316 \\
\hline Rural resident region 11 & -.9877 & .4925 & -.5442 & .4057 \\
\hline Rural resident region 13 & .2730 & .4173 & -.0734 & .3736 \\
\hline Year 1965-69 & .2557 & .0984 & .1158 & .1003 \\
\hline Year 1970-74 & .2023 & .1499 & -.0113 & .1564 \\
\hline Year 1975-79 & .5917 & .1749 & -.1312 & .1809 \\
\hline Year 1980-84 & .9673 & .2651 & .0130 & .2431 \\
\hline Year 1985-89 & 1.1391 & .3111 & .1041 & .3265 \\
\hline Year 1990-93 & .6221 & .3784 & .1172 & .4478 \\
\hline Puskesmas with family planning pre & & & & \\
\hline when woman age 7 & .0843 & .1377 & .1021 & .1360 \\
\hline Posyandu with family planning prese & & & & \\
\hline when woman age 7 & .1933 & .2450 & .2800 & .3164 \\
\hline
\end{tabular}


TABLE 4 (Continued)

\begin{tabular}{|c|c|c|c|c|}
\hline \multirow[b]{2}{*}{ Variable } & \multicolumn{2}{|c|}{ Woman } & \multicolumn{2}{|c|}{ Husband } \\
\hline & Coefficient & SE & Coefficient & SE \\
\hline \multicolumn{5}{|l|}{ Private family planning present } \\
\hline \multicolumn{5}{|l|}{ Community and regional variables: } \\
\hline \multicolumn{5}{|l|}{ Puskesmas with family planning } \\
\hline \multicolumn{5}{|l|}{ Posyandu with family planning } \\
\hline currently present & .3224 & .1673 & -.0398 & .1408 \\
\hline Private family planning currently present & .0431 & .1416 & -.0522 & .1187 \\
\hline \multicolumn{5}{|l|}{ Number of years puskesmas with } \\
\hline family planning in community & .2534 & .4205 & -.1889 & .3228 \\
\hline \multicolumn{5}{|l|}{ Number of years posyandu with } \\
\hline family planning in community & -.2285 & .4947 & .4003 & .4952 \\
\hline \multicolumn{5}{|l|}{ Number of years private family } \\
\hline planning in community & -.4538 & .4046 & .4695 & .4232 \\
\hline Gross regional domestic product & -.5893 & .7655 & -.1902 & .5127 \\
\hline Government expenditures on development & .0254 & .0132 & .0196 & .0129 \\
\hline Government expenditures on education & .0201 & .2995 & -.2000 & .2996 \\
\hline Government expenditures on family planning & .0384 & 5.6421 & .0516 & 4.7354 \\
\hline Government expenditures on health & -.7654 & .7878 & -.1261 & 1.0045 \\
\hline Student-teacher ratio in primary schools & -.0215 & .1413 & .0228 & .1312 \\
\hline Student-teacher ratio in secondary schools & -.5563 & .2768 & -.4301 & .2904 \\
\hline Student-school ratio in primary schools & .0468 & .2648 & -.0065 & .2544 \\
\hline \multirow[t]{4}{*}{ Student-school ratio in secondary schools } & .4065 & .1335 & .4017 & .1406 \\
\hline & \multicolumn{4}{|c|}{$\begin{array}{l}\text { Unobserved Heterogeneity Effects } \\
\text { for Woman's Education }\end{array}$} \\
\hline & \multicolumn{2}{|c|}{ Community } & \multicolumn{2}{|c|}{ Individual } \\
\hline & Coefficient & SE & Coefficient & SE \\
\hline \multicolumn{5}{|l|}{ Point 1 (normalized to zero) } \\
\hline Point 2 & 2.0661 & .1454 & 2.8956 & .3811 \\
\hline Point 3 & .8574 & .1194 & .7919 & .3332 \\
\hline Point 4 & -1.0933 & .1860 & .7765 & .6005 \\
\hline Point 5 & -2.7639 & .3450 & -.4540 & .4542 \\
\hline Point 6 & -.9252 & .1925 & -1.4354 & .6993 \\
\hline Point 7 & -1.2733 & .1464 & -1.5982 & 1.0753 \\
\hline Point 8 & -.2971 & .1596 & .2263 & .4623 \\
\hline Point 9 & .7638 & .1700 & .0610 & .0956 \\
\hline \multirow[t]{4}{*}{ Point 10} & -.0135 & .3569 & .4915 & .2751 \\
\hline & \multicolumn{4}{|c|}{$\begin{array}{l}\text { Unobserved Heterogeneity Effects } \\
\text { for Husband's Education }\end{array}$} \\
\hline & \multicolumn{2}{|c|}{ Community } & \multicolumn{2}{|c|}{ Individual } \\
\hline & Coefficient & SE & Coefficient & SE \\
\hline \multicolumn{5}{|l|}{ Point 1 (normalized to zero) } \\
\hline Point 2 & 1.7060 & .1692 & 1.7288 & .4387 \\
\hline Point 3 & .9003 & .1325 & -.3725 & .3699 \\
\hline Point 4 & -.7784 & .1735 & -.1107 & .7564 \\
\hline Point 5 & -.6517 & .1552 & -1.7916 & .6836 \\
\hline Point 6 & -.8243 & .2196 & -4.6370 & 2.2622 \\
\hline Point 7 & -1.0195 & .2205 & -2.9274 & .6990 \\
\hline Point 8 & -.1371 & .1717 & -.4795 & 1.2874 \\
\hline Point 9 & .3005 & .1834 & .0530 & .0871 \\
\hline Point 10 & .4166 & .3065 & .5093 & 1.6766 \\
\hline
\end{tabular}




\section{Estimates of the Coefficients Describing the Husband's Education Level}

One cannot interpret directly the husband's education estimates (also presented in table 4) as hazards of the husband leaving school, but they do describe the education level of the woman's spouse. While the single-equation estimates (not in tables) imply that women with higher education always marry men with higher education levels on average, the endogeneity-corrected estimates suggest a weaker and oftentimes reverse association between the woman's education level and the education of her chosen spouse. Again the difference in these estimates is due to the fact that the naive model merely reports the association between the spouses' schooling levels, while the heterogeneitycorrected model describes how exogenous assignment of education levels to the woman would affect the education of the spouse she would marry. There appears to be considerable sorting of spouses on unobservable traits that are strongly related to education levels; this association due to unobservable factors mostly disappears after controlling for the endogeneity of the woman's education in the determination of her husband's education. Finally, the long-term effect of exposure to each of the three family planning programs appears to result in women marrying more educated men; also, better secondary school environments, holding the wife's education constant, appear to result in her marrying a more highly educated spouse. One would reject the joint test that all three long-term effects are zero at the $10 \%$ level. From these estimates, one cannot tell if these effects are due to women in higher-quality education areas choosing more highly educated mates or if the higher quality schools in a woman's village increase the proportion of more educated men in the pool of potential spouses.

\section{Estimates of the Coefficients Determining Age at First Marriage}

Table 5 contains the estimates for the discrete-time hazard of marriage. The endogeneity-corrected estimates imply that the women with higher schooling attainments are more likely to marry at any age after they leave school than women with less education. These education effects from the endogeneitycorrected model are monotonically increasing. Relative to the coefficient for the woman being age 20, each of the heterogeneity-corrected estimates of the woman's school level is larger than the corresponding effect in the simple model (not reported in the table), and three of the four differences have $t$ statistics over 2.00. The long-term impacts of puskesmas and posyandus providing family planning services, including the age- 7 exposure measures, appear to reduce the propensity to marry, though only the posyandu effects are substantial $(-0.39$, with a composite standard error of 0.18$)$. The long-term effect of private facilities offering family planning services again has the opposite-signed 
effect than the puskesmas and posyandu. Its magnitude, however, is half that of the posyandu effect.

\section{E. Life Cycle Simulations}

While the above description of coefficients and relative effects is quite informative, it provides an incomplete picture of the effects of programs on these outcomes. In particular, because later outcomes depend on earlier endogenous outcomes, it is difficult to assess the overall impacts of schools and family planning programs on marriage, schooling, and fertility from the single-equation estimates discussed above. To provide a more complete description of the overall impacts of school quality and family planning programs, we use life cycle simulations to trace out the long-run impacts of these programs.

To do this, we start with each woman in the sample at age 7 , select her exogenous characteristics such as place of residence and migration status, and assign her to a particular combination of school quality, government health expenditures, and family planning exposures. For each age up to age 10 we simulate her school-completion decisions using the estimates from the two empirical models. Recall that our empirical model assumes that once a woman leaves school she never returns, and we impose this rule in the simulations. Starting at age 10, in addition to simulating possible school outcomes, we simulate marriage events and annual conceptions using the "hazard" estimates for these processes. Once she is simulated to become married, we use her characteristics at that point in time in a simulation of her husband's education level. After each year's simulation, we update all of the potentially time-varying variables for use in the subsequent year's simulation; we do not use any of the observed data on the endogenous outcomes in any of these simulations. We then average the outcomes of interest across all simulated women. We calculate standard errors of predictions and effects of changes in environments through parametric bootstrap procedures (250 replications) that sample from the estimated asymptotic distribution of the model parameter estimates.

We consider two different environments each for school quality, family planning programs, and government expenditures on health. For school quality, we use two different levels of the secondary school student-teacher ratio since that ratio appeared to yield the most important impacts on school outcomes. In particular, we choose a level of 17 students per teacher, roughly the 1970 level, for the poor school quality, and 12 students per teacher, roughly the 1993 level, to describe a good school environment. For the family planning exposure measures, we use no family planning programs ever as the poor family planning environment, and for the good family planning environment we 
TABLE 5

RANDOM-EFFECTS RESULTS FOR MARRIAGE EQUATION

\begin{tabular}{|c|c|c|}
\hline Variable & Coefficient & SE \\
\hline \multicolumn{3}{|l|}{ Individual-level variables: } \\
\hline Constant & -3.6593 & .9066 \\
\hline \multicolumn{3}{|l|}{ Endogenous variables: } \\
\hline Woman primary education & .2583 & .0746 \\
\hline Woman junior high education & .3045 & .1068 \\
\hline Woman senior high education & .3538 & .1203 \\
\hline Woman college education & .4235 & .1832 \\
\hline In school last year & -1.3511 & .0798 \\
\hline Woman age 15 & .8123 & .0738 \\
\hline Woman age 16 & .9661 & .0794 \\
\hline Woman age 17 & 1.4373 & .0756 \\
\hline Woman age 18 & 1.6096 & .0863 \\
\hline Woman age 19 & 1.4966 & .0952 \\
\hline Woman age 20 & 1.7175 & .0935 \\
\hline Woman age $21-22$ & 1.6156 & .0975 \\
\hline Woman age $23-24$ & 1.5941 & .1152 \\
\hline Woman age $25-26$ & 1.5900 & .1256 \\
\hline Woman age $27-28$ & 1.2643 & .1592 \\
\hline Woman age $29-30$ & .9853 & .1751 \\
\hline Respondent ever migrated & -.1171 & .1487 \\
\hline Number of moves & .3717 & .0696 \\
\hline Living in 1993 community this year & .1796 & .1366 \\
\hline Urban resident & -.5541 & .8462 \\
\hline Urban resident region 1 & -.7482 & .8528 \\
\hline Urban resident region 2 & -.8160 & .8532 \\
\hline Urban resident region 3 & -.3865 & .9198 \\
\hline Urban resident region 4 & -.1582 & .8471 \\
\hline Urban resident region 6 & -.1058 & .8401 \\
\hline Urban resident region 7 & -.4339 & .8344 \\
\hline Urban resident region 8 & -.7921 & .8635 \\
\hline Urban resident region 9 & -.2518 & .8511 \\
\hline Urban resident region 10 & -.7358 & .8650 \\
\hline Urban resident region 11 & -.2719 & .8518 \\
\hline Urban resident region 12 & -.2138 & .8530 \\
\hline Urban resident region 13 & -.7039 & .8685 \\
\hline Rural resident region 1 & -.6168 & .2618 \\
\hline Rural resident region 2 & .0004 & .2580 \\
\hline Rural resident region 3 & -.3111 & .3442 \\
\hline Rural resident region 4 & .0481 & .3445 \\
\hline Rural resident region 6 & .0776 & .2409 \\
\hline Rural resident region 7 & -.1169 & .2459 \\
\hline Rural resident region 8 & -.2313 & .3415 \\
\hline Rural resident region 9 & .0109 & .2421 \\
\hline Rural resident region 10 & -.2948 & .2929 \\
\hline Rural resident region 11 & .0529 & .3194 \\
\hline Rural resident region 13 & .1641 & .2709 \\
\hline Year 1965-69 & -.0868 & .0946 \\
\hline Year 1970-74 & -.1727 & .0880 \\
\hline Year 1975-79 & -.2402 & .0978 \\
\hline Year 1980-84 & -.2070 & .1219 \\
\hline Year 1985-89 & -.1487 & .1364 \\
\hline Year 1990-93 & -.2560 & .1829 \\
\hline Puskesmas with family planning present when woman age 7 & -.0819 & .0778 \\
\hline Posyandu with family planning present when woman age 7 & -.0189 & .1742 \\
\hline Private family planning present when woman age 7 & .0592 & .1169 \\
\hline \multicolumn{3}{|l|}{ Community and regional variables: } \\
\hline Puskesmas with family planning currently present & -.1209 & .0807 \\
\hline Posyandu with family planning currently present & .1290 & .0955 \\
\hline Private family planning currently present & .0581 & .0898 \\
\hline Number of years puskesmas with family planning in community & .1735 & .1637 \\
\hline
\end{tabular}


TABLE 5 (Continued)

\begin{tabular}{lrr}
\hline Variable & Coefficient & \multicolumn{1}{c}{ SE } \\
\hline Number of years posyandu with family planning in community & -.5029 & .2735 \\
Number of years private family planning in community & .0813 & .2121 \\
Gross regional domestic product & .1642 & .2979 \\
Government expenditures on development & -.0029 & .0090 \\
Government expenditures on education & -.2518 & .1717 \\
Government expenditures on family planning & -.0243 & 3.2561 \\
Government expenditures on health & .2537 & .3812 \\
Community heterogeneity: & & \\
Point 1 (normalized to zero) & & \\
Point 2 & -.2853 & .0933 \\
Point 3 & -.1639 & .1067 \\
Point 4 & .1767 & .1016 \\
Point 5 & .4326 & .2016 \\
Point 6 & .7693 & .1233 \\
Point 7 & .0909 & .0953 \\
Point 8 & .4232 & .0945 \\
Point 9 & -.3530 & .2932 \\
Point 10 & .3885 & .1056 \\
Individual heterogeneity: & & \\
Point 1 (normalized to zero) & & \\
Point 2 & .8720 & .6160 \\
Point 3 & 1.1909 & .5990 \\
Point 4 & 1.9055 & .6383 \\
Point 5 & 1.5951 & .6553 \\
Point 6 & .4167 & 1.1690 \\
Point 7 & 1.6238 & 1.4001 \\
Point 8 & -3.5174 & 7.7701 \\
Point 9 & .0819 & .2330 \\
Point 10 & .5286 & 1.4274 \\
\hline
\end{tabular}

impose that all three types of family planning programs came into existence 3 years before the woman was born. Again, these correspond roughly to the program characteristics in 1970 and 1993, respectively. For health expenditures, we use their average level as of 1970 for the poor environment and their 1993 level for the good environment.

Tables 6 and 7 present predicted completed children ever born and the effects of program expansions on children ever born for several combinations of the three program environments. Table 6 contains the simulation results from the random effects, heterogeneity/endogeneity-corrected model, and table 7 presents estimates from the simple model with no controls for correlated unobserved heterogeneity. The results reported in table 6 indicate that moving from an environment of no family planning programs to a full complement of family planning programs being in existence since before the woman was born would reduce fertility by almost one child per woman. These effects are significant at the $5 \%$ level against the alternative hypothesis that the effects do reduce completed fertility. Improvements in class sizes have, at most, trivial effects, while increases in government health expenditures at the district level would reduce fertility by a small but statistically significant 0.10 children per 
TABLE 6

SIMULATED IMPACTS OF FAMILY PLANNING PROGRAMS, CLASS SIZE, AND GOVERNMENT HEALTH EXPENDITURES ON CHILDREN EVER BORN, MODEL WITH HETEROGENEITY CONTROLS

\begin{tabular}{|c|c|c|c|c|c|c|c|c|}
\hline & \multicolumn{4}{|c|}{$\begin{array}{c}\text { Class Size (at Observed } 1970 \\
\text { Government Health Expenditures) }\end{array}$} & \multicolumn{4}{|c|}{$\begin{array}{l}\text { Health Expenditures (at Observed } \\
1970 \text { Class Sizes) }\end{array}$} \\
\hline & \multicolumn{2}{|c|}{$\begin{array}{c}\text { Large Class: } \\
\text { FP Programs } \\
\text { Present? }\end{array}$} & \multicolumn{2}{|c|}{$\begin{array}{c}\text { Small Class: } \\
\text { FP Programs } \\
\text { Present? }\end{array}$} & \multicolumn{2}{|c|}{$\begin{array}{c}1970 \text { Health } \\
\text { Expenditures: } \\
\text { FP Programs } \\
\text { Present? }\end{array}$} & \multicolumn{2}{|c|}{$\begin{array}{c}1993 \text { Health } \\
\text { Expenditures: } \\
\text { FP Programs } \\
\text { Present? }\end{array}$} \\
\hline & No & Yes & No & Yes & No & Yes & No & Yes \\
\hline Children ever born & $\begin{array}{c}4.91 \\
(.76)\end{array}$ & $\begin{array}{c}4.01 \\
(.83)\end{array}$ & $\begin{array}{c}4.92 \\
(.76)\end{array}$ & $\begin{array}{c}4.02 \\
(.83)\end{array}$ & $\begin{array}{c}4.91 \\
(.76)\end{array}$ & $\begin{array}{c}4.02 \\
(.83)\end{array}$ & $\begin{array}{l}4.80 \\
(.75)\end{array}$ & $\begin{array}{c}3.92 \\
(.82)\end{array}$ \\
\hline $\begin{array}{l}\text { Effect of family plan- } \\
\text { ning programs }\end{array}$ & & $\begin{array}{r}-.902 \\
(.558)\end{array}$ & & $\begin{array}{r}-.895 \\
(.557)\end{array}$ & & $\begin{array}{r}-.895 \\
(.557)\end{array}$ & & $\begin{array}{r}-.884 \\
(.548)\end{array}$ \\
\hline Effect of small class size & & & $\begin{array}{l}.003 \\
(.033)\end{array}$ & $\begin{array}{l}.010 \\
(.011)\end{array}$ & & & & \\
\hline $\begin{array}{l}\text { Effect of high health } \\
\text { expenditures }\end{array}$ & & & & & & & $\begin{array}{c}-.108 \\
(.050)\end{array}$ & $\begin{array}{l}-.09 \\
(.045)\end{array}$ \\
\hline
\end{tabular}

Note. Parametric bootstrap standard errors are in parentheses.

woman. These government health expenditure effects are also statistically significant at the $5 \%$ level. The estimates in table 7 , obtained from the estimation procedure without endogeneity controls, provide much different implications. In particular, they suggest a much smaller role for family planning programs, and they overstate considerably the effects of better schools and increased health expenditures for reducing completed fertility.

Table 8 displays the mean impacts of better schools and long-term availability of family planning programs on four demographic outcomes: completed

TABLE 7

SIMULATED IMPACTS OF FAMILY PLANNING PROGRAMS, CLASS SIZE, AND GOVERNMENT HEALTH EXPENDITURES ON CHILDREN EVER BORN, MODEL WITHOUT HETEROGENEITY CONTROLS

\begin{tabular}{|c|c|c|c|c|c|c|c|c|}
\hline & \multicolumn{4}{|c|}{$\begin{array}{c}\text { Class Size (at Observed } 1970 \\
\text { Government Health Expenditures) }\end{array}$} & \multicolumn{4}{|c|}{$\begin{array}{c}\text { Health Expenditures (at Observed } \\
1970 \text { Class Sizes) }\end{array}$} \\
\hline & \multicolumn{2}{|c|}{$\begin{array}{c}\text { Large Class: } \\
\text { FP Programs } \\
\text { Present? }\end{array}$} & \multicolumn{2}{|c|}{$\begin{array}{c}\text { Small Class: } \\
\text { FP Programs } \\
\text { Present? }\end{array}$} & \multicolumn{2}{|c|}{$\begin{array}{c}1970 \text { Health } \\
\text { Expenditures: } \\
\text { FP Programs } \\
\text { Present? }\end{array}$} & \multicolumn{2}{|c|}{$\begin{array}{l}1993 \text { Health } \\
\text { Expenditures: } \\
\text { FP Programs } \\
\text { Present? }\end{array}$} \\
\hline & No & Yes & No & Yes & No & Yes & No & Yes \\
\hline Children ever born & $\begin{array}{c}4.78 \\
(1.02)\end{array}$ & $\begin{array}{c}4.69 \\
(1.50)\end{array}$ & $\begin{array}{c}4.75 \\
(1.01)\end{array}$ & $\begin{array}{c}4.63 \\
(1.49)\end{array}$ & $\begin{array}{c}4.76 \\
(1.02)\end{array}$ & $\begin{array}{c}4.65 \\
(1.73)\end{array}$ & $\begin{array}{l}4.59 \\
(.99)\end{array}$ & $\begin{array}{c}4.49 \\
(1.46)\end{array}$ \\
\hline $\begin{array}{l}\text { Effect of family plan- } \\
\text { ning programs }\end{array}$ & & $\begin{array}{l}-.091 \\
(1.058)\end{array}$ & & $\begin{array}{l}-.124 \\
(1.050)\end{array}$ & & $\begin{array}{l}-.061 \\
(1.052)\end{array}$ & & $\begin{array}{l}-.053 \\
(1.025)\end{array}$ \\
\hline Effect of small class size & & & $\begin{array}{c}-.030 \\
(.028)\end{array}$ & $\begin{array}{l}-.062 \\
(1.058)\end{array}$ & & & & \\
\hline $\begin{array}{l}\text { Effect of high health } \\
\text { expenditures }\end{array}$ & & & & & & & $\begin{array}{r}-.177 \\
(.086)\end{array}$ & $\begin{array}{r}-.166 \\
(.093)\end{array}$ \\
\hline
\end{tabular}

Note. Parametric bootstrap standard errors are in parentheses. 
TABLE 8

SIMULATED TOTAL EFFECTS OF GOOD SCHOOLS AND FAMILY PLANNING PROGRAMS ON DEMOGRAPHIC OUTCOMES FROM HETEROGENEITY/ENDOGENEITY-CORRECTED ESTIMATES

\begin{tabular}{|c|c|c|c|c|}
\hline & $\begin{array}{c}\text { Women's Years } \\
\text { of School }\end{array}$ & $\begin{array}{l}\text { Women's Age } \\
\text { at Marriage }\end{array}$ & $\begin{array}{l}\text { Husband's } \\
\text { Education }\end{array}$ & $\begin{array}{l}\text { Children } \\
\text { Ever Born }\end{array}$ \\
\hline \multicolumn{5}{|c|}{ A. Effects of good schools versus poor schools: } \\
\hline \multicolumn{5}{|l|}{ Environment: } \\
\hline \multirow[t]{2}{*}{ No family planning } & .319 & 071 & 217 & .003 \\
\hline & (.161) & $(.036)$ & (.155) & (.066) \\
\hline \multirow[t]{2}{*}{ Complete family planning } & .296 & .071 & 221 & .010 \\
\hline & $(.155)$ & $(.038)$ & (.155) & $(.011)$ \\
\hline \multicolumn{5}{|c|}{ B. Effects of complete family planning facilities versus no family planning facilities: } \\
\hline \multicolumn{5}{|l|}{ Environment: } \\
\hline \multirow[t]{2}{*}{ Poor schools in 1970} & .953 & .886 & 1.131 & -.902 \\
\hline & (.474) & (1.1221) & $(.546)$ & (.558) \\
\hline \multirow[t]{2}{*}{ Good schools in 1993} & .930 & .885 & 1.135 & -.895 \\
\hline & (.473) & (1.221) & $(.554)$ & $(.557)$ \\
\hline
\end{tabular}

Note. The estimates in this table are evaluated at observed 1970 government health expenditures. They are policy relevant in that they answer the question of what would happen if we changed policy instruments that governments and NGOs could actually alter. The standard errors of effects are in parentheses.

school of the woman, the woman's age at marriage, the amount of education possessed by the woman's spouse, and the already-examined number of children ever born. Improvements in secondary school student-teacher ratios, on the order of magnitude of the observed average change from 1970 to 1993, do result in women attaining nearly a third of a year additional schooling. This is the case regardless of the presence of family planning programs, and it is nearly the same as Duflo's (2001) average increase in schooling due to the expansions of the Indonesian school construction programs during the 1970s. Better schools have only a negligible effect on the mean age at marriage. Better school environments appear to result in women marrying men with about onequarter of a year of additional schooling, and they do yield a moderate increase in the mean age at marriage of about 1-2 months. Improvements in the schools had almost no impact on women's completed fertility in Indonesia.

The effects of the provision of family planning programs on these same outcomes are described in the lower panel of table 8. According to these simulations based on endogeneity-corrected estimates, the effect of long-term family planning programs on education levels is three times larger than the impact of the improved schools. Family planning programs appear to lead to delays in marriage of almost a year and to women marrying men with higher education levels. The delay in marriage effects, while large, are not statistically significant. It is important to note that these family planning program effects, because they allow for more dynamic impacts of family planning programs than simple contemporaneous indicators for the presence of family planning programs, are much different from those that most studies estimate and in- 
terpret. The effects of family planning programs that we calculate are clearly quite appreciable after controlling for endogeneity.

\section{Conclusion}

This article uses a detailed stochastic dynamic theoretical model of the interactions of knowledge about family planning practices, educational decisions, and fertility outcomes as a guide for the specification of an empirical model of individual-level education, marriage, and fertility outcomes. The theoretical model indicates that contraceptive knowledge should have impacts on schooling decisions that are made well before the woman will make contraceptive decisions that influence the number of children that she will have.

The interactions among schooling choices, family planning knowledge, and fertility are quite complex. The theoretical model indicates that the "fertilityreducing" effects that are often claimed for higher female education have only a weak theoretical justification. Similarly, it need not be the case that improvements in contraceptive technologies or contraceptive knowledge will necessarily lead women to choose to increase the amount of time they spend in school. Researchers who claim such simple relationships implicitly are making statements about the relative importance of income effects, substitution effects, and self-insurance motivations. The direction and magnitudes of the impacts of knowledge about family planning on fertility and schooling, as well as the impacts of schooling on fertility, are empirical questions.

The theoretical model provides a firm foundation for the empirical model. Most important, the theoretical model reveals that it is crucial to allow the impacts of family planning services to have longer-term impacts. We incorporate such effects into our empirical specification, and we also use detailed controls for unobserved factors that could influence simultaneously the schooling, marriage, and fertility outcomes. This multiple-outcome unobserved heterogeneity model allows us to control for the endogeneity of the women's education, her husband's schooling level, and her age at marriage as determinants of her life cycle fertility.

We find that the ability of higher education to reduce fertility is seriously overstated in models that do not control for the endogeneity of education and marriage. Additionally, the estimation model without endogeneity controls dramatically understates the ability of comprehensive family planning programs to provide women with the ability and desire to reduce their completed family sizes. In our primary simulations we compare the impacts of reducing secondary school student-teacher ratios by a third to those associated with the institution of a full set of family planning programs that had been in existence since several years before a woman was born. The results indicate, for our 
examination of the Indonesia Family Life Survey data, that such comprehensive family planning programs had a much larger effect for reducing fertility than had the fertility reductions brought about by substantial improvements in school quality.

While striking, the results of this study do have important limitations. It is only for the family planning programs that we have community-level information on the provision of services. For schools and health expenditures, information about the quality of services is only available at the regional level. Additionally, approximately one-third of the women in our sample had moved since they were born; this also makes it difficult for us pinpoint exactly the woman's exposure to programs. These data issues could give rise to a form of measurement error that is due to our use of more aggregated measures for schools and other health services, and this might explain why we find such small quality of education and government health expenditure effects. Nevertheless, our results clearly indicate that endogeneity of educational attainment could be a crucial issue for program and policy evaluation. It is important for future research to explore whether controls for the endogeneity of women's education in other contexts and geographic locations would lead to similar reassessments of the importance of female education and family planning programs in developing countries.

\section{References}

Angeles, Gustavo. 1997. "Endogenous Schooling, Selective Migration, and the Estimation of the Returns to Education in Peru." PhD diss., University of North Carolina at Chapel Hill.

Angeles, Gustavo, David K. Guilkey, and Thomas A. Mroz. 1998. "Purposive Program Placement and the Estimation of Family Planning Program Effects in Tanzania." Journal of the American Statistical Association 93, no. 443 (September): 884-99. . 2004. "The Effects of Education and Family Planning Programs on Fertility in Indonesia. Working Paper no. 04-01, Department of Economics, University of North Carolina at Chapel Hill.

. Forthcoming. "The Determinants of Fertility in Rural Peru: Program Effects in the Early Years of the National Family Planning Program." Journal of Population Economics.

Becker, Gary S. 1960. "An Economic Analysis of Fertility." In Demographic and Economic Change in Developed Countries, National Bureau of Economic Research Conference Series no. 11, 209-31. Princeton, NJ: Princeton University Press.

Behrman, Jere R. 1990. “Women's Schooling and Nonmarket Productivity: A Survey and Reappraisal." Research Paper Series No. RP-147, Center for Development Economics, Williams College.

Behrman, Jere R., and Nancy Birdsall. 1983. "The Quality of Schooling: Quantity Alone Is Misleading.” American Economic Review 73, no. 5 (December): 928-46. 
Behrman, Jere R., and Mark Rosenzweig. 2002. "Does Increasing Women’s Schooling Raise the Schooling of the Next Generation?" American Economic Review 92, no. 1:323-34.

Bhargava, Alok. 1991. "Identification and Panel Data Models with Endogeneous Regressors." Review of Economic Studies 58, no. 1:129-40.

Bledsoe, Caroline, Jennifer Johnson-Kuhn, and John G. Haaga. 1999. "Introduction." In Critical Perspectives on Schooling and Fertility in the Developing World, ed. Caroline H. Bledsoe, John B. Casterline, Jennifer A. Johnson-Kuhn, and John G. Haaga. Washington, DC: National Academy.

Diamond, Ian, Margaret Newby, and Sarah Varle. 1999. "Female Education and Fertility: Examining the Links." In Critical Perspectives on Schooling and Fertility in the Developing World, ed. Caroline H. Bledsoe, John B. Casterline, Jennifer A. Johnson-Kuhn, and John G. Haaga. Washington, DC: National Academy.

Duflo, Esther C. 2001. "Schooling and Labor Market Consequences of School Construction in Indonesia: Evidence from an Unusual Policy Experiment." American Economic Review 91, no. 4 (September): 795-813.

Eloundou-Enyegue, Parfait. 1999. "Fertility and Education: What Do We Now Know?" In Critical Perspectives on Schooling and Fertility in the Developing World, ed. Caroline H. Bledsoe, John B. Casterline, Jennifer A. Johnson-Kuhn, and John G. Haaga. Washington, DC: National Academy.

Foster, Andrew D., and Nikhil Roy. 1997. "The Dynamics of Education and Fertility: Evidence from a Family Planning Experiment.” Photocopy, Department of Economics, University of Pennsylvania.

Gertler, Paul J., and John W. Molyneaux. 1994. "How Economic Development and Family Planning Combined to Reduce Fertility in Indonesia.” Demography 31:33-64.

Goldin, Claudia, and Lawrence F. Katz. 2000. "Career and Marriage in the Age of the Pill." American Economic Review 90, no. 2 (May): 461-65.

. 2002. "The Power of the Pill: Oral Contraceptives and Women's Career and Marriage Decisions." Journal of Political Economy 110, no. 4 (August): 730-70.

Heckman, James J., and Burton Singer. 1984. "A Method for Minimizing the Impact of Distributional Assumptions in Econometric Models for Duration Data." Econometrica 52:271-320.

Jejeebhoy, Shireen J. 1996. Women's Education, Autonomy, and Reproductive Behaviour: Experience from Developing Countries. Oxford: Clarendon.

Mroz, Thomas A. 1987. "The Sensitivity of an Empirical Model of Married Women's Hours of Work to Economic and Statistical Assumptions." Econometrica 55, no. 4:765-99.

- 1999. "Discrete Factor Approximations for Use in Simultaneous Equation Models: Estimating the Impact of a Dummy Endogenous Variable on a Continuous Outcome." Journal of Econometrics 92:233-74.

Mroz, Thomas A., and David K. Guilkey. 1995. "Discrete Factor Approximations for Use in Simultaneous Equation Models with Both Continuous and Discrete Endogenous Variables." Working Paper no. 95-02, Department of Economics, University of North Carolina at Chapel Hill (October).

Mroz, Thomas A., and Brian Surette. 1998. "Post-Secondary Schooling and Training 
Effects on Wage and Employment." Photocopy, Department of Economics, University of North Carolina at Chapel Hill.

Mroz, Thomas A., and David R. Weir. 1990. "Structural Change in Life Cycle Fertility during the Fertility Transition: France Before and After the Revolution of 1789." Population Studies 44 (March): 61-87.

- 2003. "Stochastic Dynamic Optimization Models with Random Effects in Parameters: An Application to Age at Marriage and Life-Cycle Fertility Control in France under the Old Regime." In History Matters: Essays in Honor of Paul A. David, ed. Timothy W. Guinnane, William Sundstrom, and Warren Whatley. Stanford, CA: Stanford University Press.

Pitt, Mark M., Mark R. Rosenzweig, and Donna Gibbons. 1993. "The Determinants and Consequences of the Placement of Government Programs in Indonesia." World Bank Economic Review 7:319-48.

Rosenzweig, Mark R., and Kenneth I. Wolpin. 1988. "Migration Selectivity and the Effects of Public Programs." Journal of Public Economics 37:265-89.

Strauss, John, and Duncan Thomas. 1996. "Human Resources: Empirical Modeling of Household and Family Decisions." In Handbook of Development Economics, ed. J. R. Behrman and T. N. Srinavasan. Amsterdam: North Holland.

Summers, Lawrence H. 1992. "Investing in All the People." World Bank Policy Research Working Paper no. 905, World Bank, Washington, DC.

Thomas, Duncan. 1999. "Fertility, Education, and Resources in South Africa." In Critical Perspectives on Schooling and Fertility in the Developing World, ed. Caroline H. Bledsoe, John B. Casterline, Jennifer A. Johnson-Kuhn, and John G. Haaga. Washington, DC: National Academy.

World Bank. 1992. "Educating Girls Has a High Payoff." Development Brief no. 2 (21628 [October]), World Bank, Washington, DC. 